\title{
The Amsterdam Wrist Rules: how much money can they save?
}

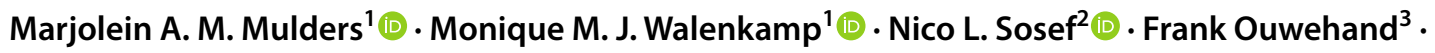 \\ Romuald van Velde ${ }^{4} \cdot$ J. Carel Goslings ${ }^{5}$ - Niels W. L. Schep ${ }^{6}$
}

Received: 17 December 2019 / Accepted: 10 February 2020 / Published online: 17 March 2020

(c) The Author(s) 2020

\begin{abstract}
Purpose To allow physicians to be more selective in their request for a radiograph of the wrist and to potentially reduce costs, the Amsterdam Wrist Rules (AWR) have been developed, externally validated, and recently also implemented. The aim of this study was to conduct an incremental cost analysis and budget impact analysis of the implementation of the AWR at the emergency department (ED) in the Netherlands.

Methods A cost-minimisation analysis to determine the expected cost savings for implementation of the Amsterdam Wrist Rules. The incremental difference in costs before and after implementation of the AWR was based on the reduction in costs for radiographs, the cost savings due to reduction of ED consultation times and the costs of a re-evaluation appointment by a physician. Results In the Netherlands, implementation of the AWR could potentially result in $6 \%$ cost savings per patient with a wrist injury. In addition, implementation of the AWR resulted in $€ 203,510$ cost savings annually nationwide. In the sensitivity analysis, an increase in physician compliance to $100 \%$ substantially increased the potential total amount of annual cost savings to $€ 610,248$, which is $6 \%$ of total costs before implementation. Variation in time spent at the ED, a decrease and increase in costs and patients presenting annually at the ED did not change the cost savings substantially.

Conclusion Implementation of the AWR has been shown to reduce direct and indirect costs and can, therefore, result in considerable savings of healthcare consumption and expenditure.
\end{abstract}

Keywords Distal radius $\cdot$ Fracture $\cdot$ Trauma $\cdot$ Decision rule $\cdot$ Radiograph $\cdot$ Cost analysis

JEL Classification I100

Electronic supplementary material The online version of this article (https://doi.org/10.1007/s10198-020-01168-x) contains supplementary material, which is available to authorized users.

Marjolein A. M. Mulders

m.a.mulders@amsterdamumc.nl

1 Trauma Unit, Department of Surgery, Amsterdam UMC, Academic Medical Center, University of Amsterdam, P.O. Box 22660, 1100 DD Amsterdam, The Netherlands

2 Department of Surgery, Spaarne Gasthuis, P.O. Box 770, 2130 AT Hoofddorp, The Netherlands

3 Emergency Department, Amsterdam UMC, Academic Medical Center, University of Amsterdam, P.O. Box 22660, 1100 DD Amsterdam, The Netherlands

4 Department of Surgery, Tergooi Hospitals, P.O. Box 10016, 1201 DA Hilversum, The Netherlands

5 Department of Surgery, Onze Lieve Vrouwe Gasthuis, P.O. Box 95500, 1090 HM Amsterdam, The Netherlands

6 Department of Trauma and Hand Surgery, Maasstad Hospital, P.O. Box 9100, 3007 AC Rotterdam, The Netherlands

\section{Introduction}

A trauma of the wrist is a common reason for a patient to present at the emergency department (ED). However, only half of the patients who present at the ED have sustained a fracture of the wrist $[1,2]$. Nonetheless, almost all patients undergo radiographs of the wrist. Even though the costs per radiograph are limited, due to the high incidence of wrist trauma the cumulative costs can be substantial. The estimated total healthcare costs for wrist fractures in the Netherlands are 83 million euro per year, making them the most expensive injuries of the upper extremity $[3,4]$.

To allow physicians to be more selective in their request for a radiograph, the Amsterdam Wrist Rules (AWR) have been developed, externally validated [1], and recently also implemented [5]. Based on the age of the patient and several clinical variables present during physical examination, the AWR provide a recommendation to request a radiograph of the wrist or not in patients suspected of a distal radius 
fracture. After implementation of the AWR, an absolute reduction of $15.3 \%$ in wrist radiographs was found, without missing any clinically relevant fractures. Moreover, due to the AWR non-fracture patients without a wrist radiography spent 34 min less at the ED compared with non-fracture patients who had a wrist radiograph. This reduction in radiographs requested and time spent at the ED could potentially result in cost savings.

Therefore, the aim of this study was to conduct an incremental cost analysis for the implementation of the AWR at the ED in the Netherlands. Secondary, we aimed to conduct a budget impact analysis to estimate the total impact on the healthcare budget in the Netherlands.

\section{Methods}

In this study, we used a diagnostic technology evaluation to determine the expected cost savings for the implementation of the Amsterdam Wrist Rules [6]. The total costs of treatment for two cohorts of patients were calculated based on their use of resources. Data were retrieved from the recent implementation study of the Amsterdam Wrist Rules [5]. This before and after study, compared 402 patients in which the AWR were implemented (after group), with a prospectively collected historical reference group of 859 patients in which the AWR were not yet implemented (before group). The estimates of fracture prevalence and the reduction in radiographs were based on this recent implementation study. Patients in the after group were included using a smartphone application developed for use of the AWR. All patients that did not receive a radiograph of the wrist were telephoned after 1 week to determine if a fracture was missed and if any subsequent physician appointments or radiographs were performed.

The baseline characteristics age, gender and percentage of distal radius fractures of the before and after group were comparable (Table 1). The absolute reduction in wrist radiographs was $15.3 \%$ (99.4\% versus $84.1 \% ; p<0.001)$; before the implementation of the AWR, in $0.6 \%$ of patients no

Table 1 Baseline characteristics before and after implementation of the AWR

\begin{tabular}{llll}
\hline & $\begin{array}{l}\text { Before imple- } \\
\text { mentation } \\
\text { AWR }\end{array}$ & $\begin{array}{l}\text { After imple- } \\
\text { mentation } \\
\text { AWR }\end{array}$ & $p$ value \\
& $N=859$ & $N=402$ & \\
\hline Age [median (IQR)] & $50(31-63)$ & $51(32-67)$ & 0.294 \\
Female (\%) & 60.5 & 60.7 & 0.957 \\
Distal radius fractures (\%) & 43 & 44 & 0.814 \\
Wrist radiographs (\%) & 99.4 & 84.1 & $<0.001$ \\
\hline
\end{tabular}

$N$ number, $I Q R$ interquartile range radiograph was requested, compared to $15.9 \%$ after implementation. $36 \%$ of the physicians adhered to the recommendation. Non-fracture patients without a wrist radiography due to the AWR spent 34 min less at the ED compared with non-fracture patients who had a wrist radiograph $(p=0.015)$. This comprises a $29 \%$ reduction in time spent at the ED compared with the period before implementation of the AWR [5].

One patient had a subsequent outpatient clinic appointment and wrist radiograph because she still had complaints when she was phoned after 1 week. She received a removable splint for 4 weeks for a clinically irrelevant fracture.

\section{Cost analysis}

Considering that the AWR should not result in differences in health outcomes, the economic evaluation was set up as a cost-minimisation analysis and addressed direct medical costs (i.e. use of radiographs, consultation at the ED and other healthcare providers, decrease in the length of the ED consultation) and nonmedical costs (i.e. travel expenses to the ED and for additional hospital appointments). Costs for each consultation at the ED (both with and without a radiograph) were estimated and any additional consultations at the ED or other healthcare providers were also included. It was assumed that no missed fracture would remain undetected indefinitely and that possible fractures missed at the ED due to the AWR would not have been missed if the patient had undergone radiography. Therefore, we considered additional radiographs and treatment related to missed fractures as delayed costs and not as additional costs. The subsequent outpatient clinic appointment and travel expenses to the outpatient clinic were considered as the only additional medical cost. Cost savings realized by shorter consultation times at the ED were considered as well since this time could be spent for another patient resulting in better use of resources. Since we did not expect that a delayed diagnosis would influence the absence at work, we did not take into account the productivity loss of patients. Moreover, since the variables of the AWR are part of the physical examination, we considered the additional time of completing the mobile application negligible.

Charges (in Euros) of radiographs of the wrist, ED consultations and outpatient clinic appointments, and travel expenses were obtained from the Dutch costs manual 2016 and extrapolated to 2015 using the consumer price index [7]. Travel expenses were based on a charge of 19 euro cents per kilometre, with an average travel distance of seven kilometres. An additional three euros was added for the parking fee. Values of all costs used in this analysis are displayed in Table 2. Since the AWR had a $100 \%$ sensitivity on detecting clinically relevant fractures, the baseline analysis focused on the incremental cost difference between standard practice 
Table 2 Costs per item

\begin{tabular}{ll}
\hline ED consultation & 260.55 \\
ED consultation with reduction in length of stay at ED & 185.51 \\
Outpatient clinic appointment & 91.55 \\
Radiograph of wrist & 47.02 \\
Travel expenses & 4.36 \\
\hline
\end{tabular}

All values are displayed in Euros

$E D$ emergency department

and application of the AWR. A sensitivity analysis was performed on increasing the physician compliance, the time spent at the ED, and increasing and decreasing the costs for a radiograph, the consultation at the ED, and additional outpatient clinic appointment.

With these assumptions, the incremental difference in costs before and after implementation of the AWR was based on the reduction in costs for wrist radiographs, the cost savings due to reduction of ED consultation times and the costs of a re-evaluation appointment by a physician.

\section{Budget impact analysis}

In a budget impact analysis, the study results of the cost analysis were extrapolated to the national level to estimate the total impact on the healthcare budget per annum for the Netherlands in terms of health benefits. The budget impact analysis was based on an estimated number of 34,500 adult patients with a trauma of the wrist presenting annually at the ED. This number was based on the Dutch Injury Surveillance System (LIS) [8]. This national registry registers all trauma patients who present at the ED of a representative sample of hospitals in the Netherlands.

A sensitivity analysis was performed on increasing physician compliance, and time spent at the ED. Moreover, a sensitivity analysis was performed on increasing and decreasing the costs for a radiograph and additional outpatient clinic appointment, and the number of patients presenting at the ED.

\section{Results}

\section{Cost analysis}

Table 3 shows the (incremental) cost savings in the total cohort of 402 patients. Considering an absolute reduction of $15.3 \%$ in wrist radiographs $(99.4 \%$ requested radiographs before implementation versus $84.1 \%$ after implementation), the total cost savings after implementation of the AWR were $€ 2420$ for the baseline analysis. This is $2 \%$ savings per patient with a wrist injury after implementation of the AWR.

In the sensitivity analysis, when considering the reduction in radiographs due to an increase in physician compliance of $50 \%, 75 \%$ and $100 \%$, a total amount of $€ 3519$, €5472 and $€ 7425$, respectively, could potentially be saved. When considering a $100 \%$ physician compliance, the savings per patient tripled to $6 \%$. If the reduction in ED length of stay would be decreased to $15 \%$, the difference in costs decreased as well (cost savings $€ 1665$ ). In contrast, if the reduction in ED length of stay would be increased to $40 \%$, the difference in costs was increased as well (cost savings €3034). The same applied if the costs for a radiograph, the consultation at the ED, and additional outpatient clinic appointment would be decreased and increased with $15 \%$ ( $€ 2057$ and $€ 2784$ cost savings, respectively) (Fig. 1, Appendix 1).

\section{Budget impact analysis}

Finally, the cost savings were translated to cost savings for the Dutch population (Table 4). In the Netherlands, an estimated number of 34,500 patients annually present at the ED due to a trauma of the wrist. Based on this number of patients, implementation of the AWR resulted in $€ 203,510$ cost savings per year.

In the sensitivity analysis, the potential total cost savings based on an increase in physician compliance varied between $€ 610,247$ (100\% physician compliance), €451,311 (75\% physician compliance) and $€ 292,490$ (50\% physician
Table 3 Base case analysis for cost savings

\begin{tabular}{|c|c|c|c|c|}
\hline & \multicolumn{2}{|c|}{ Before implementation } & \multicolumn{2}{|c|}{ After implementation } \\
\hline & $\begin{array}{l}\text { Number of } \\
\text { patients }\end{array}$ & Total costs & $\begin{array}{l}\text { Number of } \\
\text { patients }\end{array}$ & Total costs \\
\hline ED consultation & 402 & 104,222 & 379 & 98,750 \\
\hline ED consultation without wrist radiograph & 2 & 371 & 23 & 4267 \\
\hline Outpatient clinic appointment & 0 & - & 1 & 92 \\
\hline Radiograph of wrist & 400 & 18,808 & 380 & 17,868 \\
\hline Travel expenses & 402 & 1751 & 403 & 1755 \\
\hline Total base case & & 125,152 & & 122,732 \\
\hline
\end{tabular}

All values are displayed in Euros

$E D$ emergency department 
Fig. 1 Cost savings after implementation of the AWR, including sensitivity analysis
- Before implemenation

- After implementation

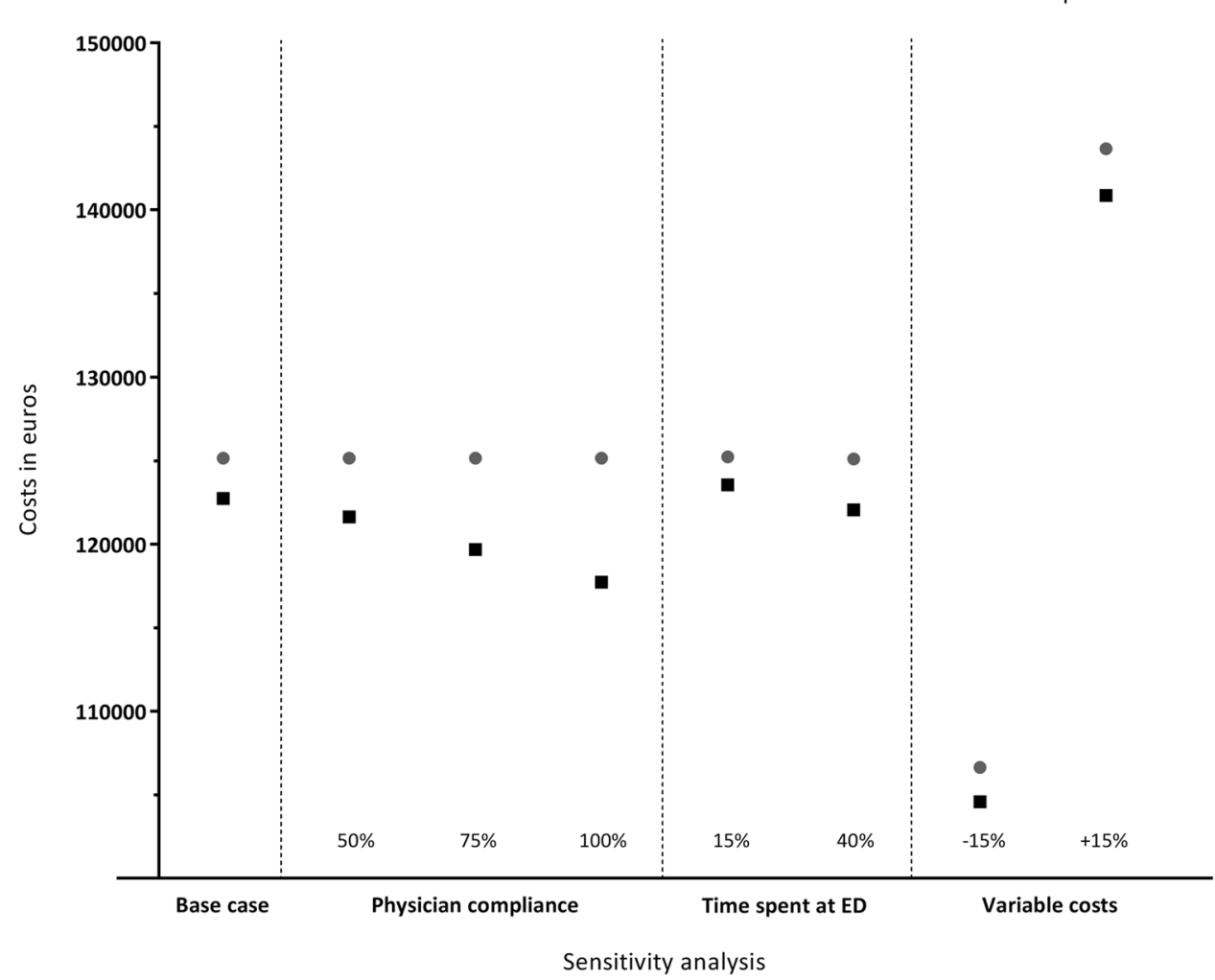

Table 4 Base case analysis for budget impact analysis

\begin{tabular}{|c|c|c|c|c|}
\hline & \multicolumn{2}{|c|}{ Before implementation } & \multicolumn{2}{|c|}{ After implementation } \\
\hline & $\begin{array}{l}\text { Number of } \\
\text { patients }\end{array}$ & Total costs & $\begin{array}{l}\text { Number of } \\
\text { patients }\end{array}$ & Total costs \\
\hline ED consultation & 34,293 & $8,935,178$ & 32,525 & $8,474,519$ \\
\hline ED consultation without wrist radiograph & 207 & 38,401 & 1,975 & 366,391 \\
\hline Outpatient clinic appointment & 0 & - & 86 & 7873 \\
\hline Radiograph of wrist & 34,293 & $1,612,473$ & 32,611 & 150,656 \\
\hline Travel expenses & 34,500 & 150,281 & 34,586 & $1,533,385$ \\
\hline Total base case & & $10,736,334$ & & $10,532,824$ \\
\hline
\end{tabular}

All values are displayed in euros

$E D$ emergency department compliance). The cost savings after increasing the physician compliance to $100 \%$, is $6 \%$ of total costs before implementation. In addition, if the reduction in time spent at the ED was assumed to decrease to $15 \%, € 139,954$ was saved. In contrast, if the reduction in time spent at the ED was assumed to increase to $40 \%, € 255,089$ was saved. Moreover, a decrease of $15 \%$ in costs would result in $€ 172,943$ cost savings, and an increase of $15 \%$ would result in $€ 234,078$ cost savings.

Last, keeping in mind a different estimated number of patients presenting at the ED in the Netherlands annually, the cost savings would be $€ 183,193$, based on an estimated number of 31,050 patients ( $10 \%$ decrease), and $€ 223,850$, based on an estimated number of 37,950 patients (10\% increase) presenting at the ED annually (Fig. 2, Appendix 2).

\section{Discussion}

In this study, the cost analysis and budget impact analysis of implementation of the AWR at the ED in the Netherlands was established under a variety of different assumptions. Based on the 402 included patients, implementation of the AWR results in $€ 2420$ cost savings. When increasing the physician compliance to $100 \%$, implementation 
Fig. 2 Budget impact analysis after implementation of the AWR, including sensitivity analysis
- Before implemenation

- After implementation

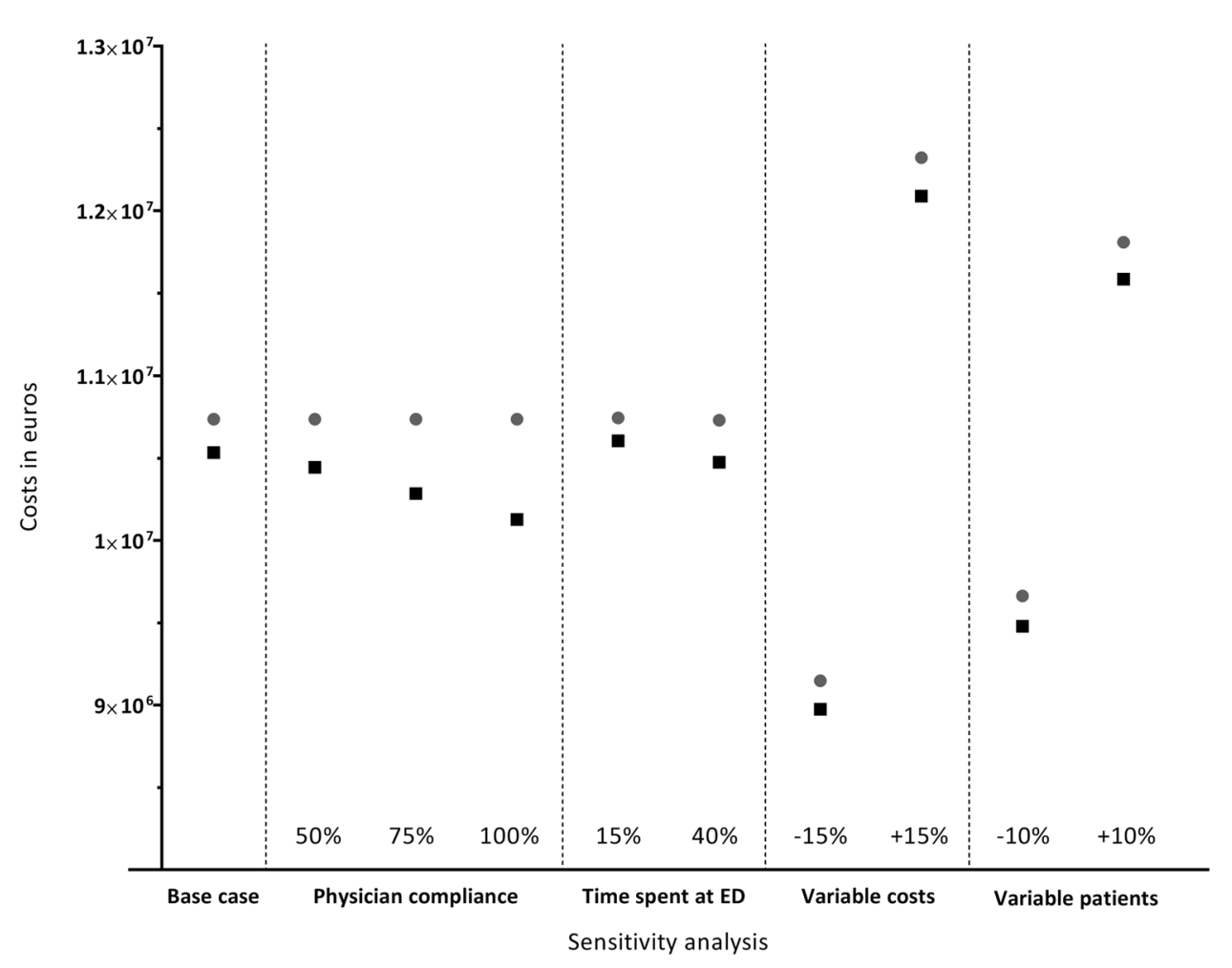

of the AWR could potentially result in $6 \%$ cost savings per patient with a wrist injury. Additionally, based on an estimated number of 34,500 patients annually presenting at the ED with a trauma of the wrist, implementation of the AWR could potentially reduce the costs with $€ 203,511$. Sensitivity analysis that varied the time spent at the ED, the rate of costs for a radiograph and additional outpatient clinic appointment, and the amount of patients presenting at the ED, did not change the results substantially. Yet, under each assumption of the sensitivity analysis, implementation of the AWR resulted in cost savings compared to current practice. Moreover, an increase in the physician compliance tripled the decrease in costs for both the cost analysis and the budget impact analysis to an amount of $€ 7425$ and $€ 610,248$ (both $6 \%$ of total costs before implementation), respectively.

The potential cost savings of the implementation of the AWR could be beneficial for hospitals or healthcare insurance companies. Although these savings may not result in a significant reduction in the total annual healthcare expenditures, they liberate resources that can be used elsewhere resulting in better use of resources at the ED. In contrast to the total annual healthcare expenditures of approximately 95 billion euro in the Netherlands in 2015, the reduction of radiographs, which individually costs little but which is frequently used by physicians, could account for far more in the annual growth of healthcare expenditures than do a few big technologies [9].

Since this study was conducted using a societal perspective, time spent at the ED was incorporated. Ideally, this should be calculated by analyzing the willingness to pay of these patients for time-saving activities [10]. However, we assumed that a $29 \%$ reduction in time spent at the ED after implementation of the AWR, equalled the percentage of costs saved. Loss of productivity was not taken into account since we assumed that a delayed diagnosis would not result in additional days off work. Yet, the cost for the additional outpatient clinic appointment and the delayed radiograph were taken into account. To control for potential errors in this assumption, a sensitivity analysis was performed by decreasing and increasing the length of stay at the ED and thereby the costs. Although the different sensitivity analyses did not change the results of both the cost analysis and the budget-impact analysis substantially, increasing the compliance of the physicians to $100 \%$ tripled the costs savings. We expect that, by demonstrating that the AWR can safely be used, the adherence of physicians towards the AWR will increase in the future and therefore increasing the cost savings. Moreover, despite the evidence that the AWR can safely reduce the amount of wrist radiographs requested and thereby reducing costs, physicians may still feel uncomfortable about using the AWR. This is mostly 
related to the concern of missing a fracture in patients who did not receive a wrist radiograph, and the possible medicolegal consequences [11]. However, if the AWR will be generally accepted as good clinical practice and endorsed by (inter)national societies, it is not very likely that implementation would lead to liability $[12,13]$.

Finally, radiography of the wrist was assumed to have a $100 \%$ sensitivity and specificity for identifying fractures of the distal radius, and therefore we assumed that no fractures were missed in the before group. Although the physicians' ability to rule out a distal radius fracture is high [14], fractures of the distal radius are sometimes missed. Either because of misinterpretation of the physician or because the fracture was not visible on radiography. Therefore, it is possible that the assumption of no missed fractures in the before group was an underestimation, causing an underestimation of the cost difference.

In conclusion, the AWR have been shown to safely reduce the number of wrist radiographs requested at the ED and consequently the time spent at the ED. Moreover, after the incorporation of direct and indirect costs, the implementation of the AWR has also been shown to reduce costs. Implementation of the AWR would, therefore, result in considerable savings of healthcare expenditures, and supports the introduction of the AWR into clinical practice, from both a clinical as well as health economic point of view.

Acknowledgements We thank all emergency department physicians, residents, and emergency department personnel at the participating sites for patient inclusion; and R. Detering (research student) for the assistance in data completion.

Funding This work was supported by ZonMw, the Netherlands Organisation for Health Research and Development [Grant number 837001407].

\section{Compliance with ethical standards}

Conflict of interest Dr. Mulders, Walenkamp, Sosef, Ouwehand, Van Velde, Goslings and Schep declare that they have no conflicts of interest.

Open Access This article is licensed under a Creative Commons Attribution 4.0 International License, which permits use, sharing, adaptation, distribution and reproduction in any medium or format, as long as you give appropriate credit to the original author(s) and the source, provide a link to the Creative Commons licence, and indicate if changes were made. The images or other third party material in this article are included in the article's Creative Commons licence, unless indicated otherwise in a credit line to the material. If material is not included in the article's Creative Commons licence and your intended use is not permitted by statutory regulation or exceeds the permitted use, you will need to obtain permission directly from the copyright holder. To view a copy of this licence, visit http://creativecommons.org/licenses/by/4.0/.

\section{References}

1. Walenkamp, M.M., Bentohami, A., Slaar, A., Beerekamp, M.S., Maas, M., Jager, L.C., et al.: The Amsterdam wrist rules: the multicenter prospective derivation and external validation of a clinical decision rule for the use of radiography in acute wrist trauma. BMC Musculoskelet. Disord. 16(1), 389 (2015)

2. van den Brand, C.L., van Leerdam, R.H., van Ufford, J.H., Rhemrev, S.J.: Is there a need for a clinical decision rule in blunt wrist trauma? Injury 44(11), 1615-1619 (2013)

3. Polinder, S., Iordens, G.I.T., Panneman, M.J.M., Eygendaal, D., Patka, P., Den Hartog, D., et al.: Trends in incidence and costs of injuries to the shoulder, arm and wrist in The Netherlands between 1986 and 2008. BMC Public Health 13, 531 (2013)

4. Meerding, W.J., Mulder, S., van Beeck, E.F.: Incidence and costs of injuries in The Netherlands. Eur. J. Public Health 16, 272-278 (2006)

5. Mulders, M.A.M., Walenkamp, M.M.J., Sosef, N.L., Ouwehand, F., van Velde, R., Goslings, C., et al.: The Amsterdam wrist rules to reduce the need for radiography after a suspected distal radius fracture: an implementation study. Eur. J. Trauma. Emerg. Surg. 2019, 1 (2019)

6. Phelps, C.E., Mushlin, A.I.: Focusing technology assessment using medical decision theory. Med. Decis. Making 8(4), 279-289 (1988)

7. Hakkaart-van Roijen L, van der Linden N, Bouwmans C, Kanters T, Tan SS (2017) Kostenhandleiding: Methodologie van kostenonderzoek en referentieprijzen voor economische evaluaties in de gezondheidszorg: Zorginstituut Nederland 2015. https:// www.zorginstituutnederland.nl/binaries/zinl/documenten/publi catie/2016/02/29/richtlijn-voor-het-uitvoeren-van-economisch e-evaluaties-in-de-gezondheidszorg/Richtlijn+voor+het+uitvo eren+van+economische+evaluaties + in + de+gezondheidszorg +\%28verdiepingsmodules\%29.pdf. Accessed 2 Nov 2017

8. Letsel Informatie Systeem. Bron: Letsel Informatie Systeem 2014, VeiligheidNL. https://www.veiligheid.nl/organisatie/monit oring-onderzoek/letsel-informatie-systeem?gclid=EAIaIQobCh MI_qPStLG95gIVCLDtCh0B0AYxEAAYASAAEgKa8fD_BwE. Accessed 10 May 2016

9. Maloney, T.W., Rogers, D.E.: Medical technology: a different view of the coententious debate over costs. N. Engl. J. Med. 301, 1413-1419 (1979)

10. Beesley, M.E.: The value of time spent traveling: some new evidence. Economica 32, 174-185 (1965)

11. Long, A.E.: Radiographic decision-making by the emergency physician. Emerg. Med. Clin. North Am. 3(3), 437-446 (1985)

12. Jutras, D.: Clinical practice guidelines as legal norms. CMAJ 148(6), 905-908 (1993)

13. Brand, D.A., Frazier, W.H., Kohlhepp, W.C., Shea, K.M., Hoefer, A.M., Ecker, M.D., et al.: A protocol for selecting patients with injured extremities who need x-rays. N. Engl. J. Med. 306(6), 333-339 (1982)

14. Walenkamp, M.M., Rosenwasser, M.P., Goslings, J.C., Schep, N.W.: A multicentre cross-sectional study to examine physicians' ability to rule out a distal radius fracture based on clinical findings. Eur. J. Trauma. Emerg. Surg. 42(2), 185-190 (2016)

Publisher's Note Springer Nature remains neutral with regard to jurisdictional claims in published maps and institutional affiliations. 